\title{
Uma proposta de tradução do sexto mandamento de Deus em um confessionário Tupi da Amazônia de $1751^{*}$
}

\author{
Ruth Monserrat ${ }^{* * *}$ \\ Jaqueline Mota ${ }^{* * * *}$
}

Maria Cândida Barros**

O objetivo é transcrever e traduzir para o português as perguntas de um confessionário tupi (1751) do Pará, referentes ao sexto mandamento. Basearemos a tradução na metodologia lingüística, usando dicionários tupi coloniais. Propomos uma análise de radicais tupi usados pelos missionários para traduzir conceitos da sexualidade cristã. O documento pertence à Biblioteca Nacional do Rio de Janeiro.

Palavras-chave: Confessionário Tupi - Tradução - Sexto Mandamento

A proposal for the translation of the Sixth Commandment in a Tupi confessionary from Amazonia, 1751

The present article transcribes and translates into Portuguese questions relating to the Sixth Commandment taken from a 1751 Tupi confessionary from Pará which

\footnotetext{
* Artigo recebido em dezembro de 2007 e aprovado para publicação em março de 2008. O trabalho recebeu o apoio do Programa de Pesquisa da Fundação Biblioteca Nacional, CNPq e MCT-PCI.

** Pesquisadora do Museu Paraense Emílio Goeldi. E-mail: mcandida.barros@gmail.com.

**** Universidade Federal do Rio de Janeiro. E-mail: ruth.monserrat@gmail.com.

**** Graduada em História pela Universidade Federal do Pará. E-mail: jaquemota@gmail.com.
} 
currently resides in the Brazilian National Library in Rio de Janeiro. Our translation is based on linguistic methodology using colonial Tupi dictionaries and we have carried out an analysis of the Tupi radicals used by missionaries to translate concepts of Christian sexuality.

Keywords: Tupi Confessionary - Translation - Sixth Commandment

\section{Une proposition de traduction du Sixième Commandement de Dieu dans un} Livre de Confession Tupi de l'Amazonie (1751)

L'objectif de ce travail est de transcrire et traduire en portugais les questions provenant d'un Livre de Confession tupi au Para (1751) qui se rapportent au Sixième Commandement (sur la chasteté). La traduction emploie la méthodologie linguistique et fait recours aussi aux dictionnaires tupi coloniaux. Une analyse des radicaux tupi employés par les missionnaires pour traduire des concepts de la sexualité chrétienne est proposée. Le document original appartient à la Bibliothèque Nationale de Rio de Janeiro.

Mots-clés: Livre de Confession Tupi - Traduction - Sixième Commandement

\section{Introdução}

Um confessionário tupi anônimo, usado em alguma missão do Pará, em $1751,{ }^{1}$ está organizado por meio de perguntas para cada mandamento da Lei de Deus, a exemplo das obras congêneres européias. Nossa atenção estará dirigida às perguntas referentes ao sexto mandamento (castidade). Para esse trecho do confessionário, proporemos um exercício de tradução para o português, usando como fontes auxiliares dicionários tupi coloniais, ${ }^{2}$ e como método a análise lingüística. A tradução, ainda vacilante em alguns pontos, permitirá acompanhar as modalidades de pecado (por palavra, ação e pensamento) que o missionário investigava e interditava e algumas diferenças de conteúdo e de formas na maneira de interrogar homens e mulheres.

\footnotetext{
${ }^{1}$ Anônimo, Vocabulario de lingoa brasilica, Rio de Janeiro, Fundação Biblioteca Nacional, 1751.

${ }^{2}$ Utilizaremos na análise os manuscritos: Anônimo, Gramatica da Lingua geral do Brasil com hum Diccionario dos vocabulos mais u\&uaes para a intelligencia da dita Lingua, Coimbra, Biblioteca da Universidade de Coimbra, 1750; Anônimo, Diccionario da Lingua geral do Brasil que se falla em todas as villas, lugares e aldeas deste vastissimo Estado, Escrito na Cidade do Pará, Coimbra, Biblioteca da Universidade de Coimbra, 1771; Anônimo, Vocabulario da Lingua Brazil, Lisboa, Biblioteca Nacional, s.d.
} 
A tradução de um fragmento de um confessionário tupi do Pará, em 1751, se propõe difundir um texto ainda inédito da evangelização da Amazônia. Para futuro, a comparação do diálogo da confissão dos pecados da carne na Amazônia, em 1751, com aqueles usados por Anchieta no século XVI e por Araújo no século XVII, para a mesma situação comunicativa, permitirá uma melhor compreensão das continuidades e descontinuidades da evangelização jesuítica nas duas regiões.

A opção por editar um texto ligado à confissão se deve a ser esse um dos poucos diálogos da conversão no qual índio e missionário se encontravam frente a frente. $O$ documento permitirá a análise das estratégias e das posturas do missionário em um diálogo sobre sexo com os índios. Em anexo, seguem a transcrição e a tradução das perguntas referentes ao sexto mandamento.

\section{Incursão de historiadores às fontes coloniais em línguas indígenas}

A sugestão para traduzir uma passagem de um confessionário tupi veio da experiência de grupos de historiadores que trabalham com fontes coloniais em línguas indígenas. Esses textos têm deixado de ser espaço apenas para análise de lingüistas para se tornarem fontes documentais primordiais para historiadores. Entre esses, é possível reconhecer dois grupos que apresentam diferenças em relação ao gênero de texto em língua indígena enfatizado em suas análises e em relação à caracterização teórica dessas línguas no processo de mudança cultural pela colonização.

Um grupo de historiadores inovadores no uso das fontes em língua indígenas foi o da Nova Filologia, liderado por James Lockhart e seus discípulos. ${ }^{3}$ A marca registrada dessa corrente foi a tradução, edição e análise de fontes notariais - escritas no alfabeto latino - em nahuatl, mixteco, maia e quechua. Essa corrente se ocupou de testamentos, petições, listas etc., não se preocupando, no entanto, com fontes missionárias, desprezadas por não representarem o ponto de vista nativo, passível de ser recuperado pelas inscrições notariais de responsabilidade de índios da colonização hispânica. Lockhart vislumbrou nas fontes em línguas indígenas aspectos da colonização que não poderiam ser analisados nas fontes em espanhol.

Uma das análises clássicas de Lockhart sobre as fontes notariais em nahuatl centrou-se nos diferentes padrões de empréstimos do espanhol, presentes naqueles textos, entre os séculos XVI e XVII, como evidências de

\footnotetext{
${ }^{3}$ Para uma revisão dessa corrente na historiografia ver Matthew Restall, "A History of the New Philology and the New Philology in History", Latin American Research Review, v. 38, n. 1, Austin, 2003, p. 113-134.
} 
aculturação. Ele correlaciona diferenças na quantidade, na categoria gramatical e no campo semântico dos empréstimos a mudanças sociais. Por exemplo, a maior quantidade de empréstimos (alguns sendo verbos e preposições) ocorreu a partir de 1640-50, quando o sistema de repartimento estava sendo substituído por acordos individuais entre índios e espanhóis para negociação dos salários. O contato maior entre índios e colonizadores explicaria o maior número de empréstimos.

Ao atribuir a presença do espanhol nos textos notariais indígenas como evidência do contato colonial, Lockhart estaria definindo o uso do nahuatl como marca da vitalidade da cultura indígena, em oposição ao espanhol analisado pelos empréstimos -, que expressaria o processo de aculturação em curso. Um exemplo dessa concepção sobre a língua indígena pode ser encontrado na análise das mudanças culturais da colonização na Amazônia proposta por Sweet. ${ }^{4}$ Em sua definição de aldeia, considera que o uso da língua geral, assim como o uso da mandioca como alimentação principal, seriam indícios da presença da cultura indígena, enquanto os aspectos europeus estariam presentes na vida religiosa e na forma de exploração do trabalho nas missões. ${ }^{5}$ Nesse modelo, a cultura indígena (=língua) e a européia eram dois padrões de vida diferentes e justapostos no cotidiano das missões.

"Aldeia". Indian settlement under missionary administration with a semi-European social structure, religious life, labor system and physical layout - but retaining to a large extent indigenous language, customs and subsistence patterns. ${ }^{6}$

Diferentemente de Lockhart, outro grupo de historiadores voltou sua atenção para as fontes em línguas indígenas, privilegiando, porém, os textos missionários. Entre eles, estão Rafael, ${ }^{7}$ Estenssoro, ${ }^{8}$ Monteiro, ${ }^{9}$ Pompa,${ }^{10}$ Ag-

\footnotetext{
${ }^{4}$ David Graham Sweet, A Rich Realm of Nature Destroyed: The Middle Amazon Valley, 16401750, Madison, University of Wisconsin, 1974.

${ }^{5}$ David Graham Sweet, idem, p. 807.

${ }^{6}$ Idem.

${ }^{7}$ Vicente Rafael, Contracting Colonialism: Translation and Christian Conversion in Tagalog Society under Early Spanish Rule, Ithaca, Cornell University Press, 1988.

${ }^{8}$ Juan Carlos Estenssoro Fuchs, Del Paganismo a la Santidad: La Incorporación de los Indios del Peru al Catolicismo (1532-1750), Lima, IFEA, 2003.

${ }^{9}$ John Manuel Monteiro, Tupis, Tapuias e Historiadores: Estudos de História Indígena e do Indigenismo, Tese apresentada para o Concurso de Livre Docência, Departamento de Antropologia, Campinas: IFCH - Unicamp, 2001, p. 36-52.

${ }^{10}$ Maria Cristina Pompa, "Para uma antropologia histórica das missões", in: Paula Montero (org.), Deus na aldeia: missionários, indios e mediação cultural, São Paulo, Editora Globo, 2006.
} 
nolin. ${ }^{11}$ Uma das diferenças entre esses autores e a Nova Filologia é a crítica que fazem ao conceito de aculturação, definido como perda da cultura original pela imposição de valores ocidentais via evangelização. Essa corrente opta pelo conceito de interpenetração de civilizações, ${ }^{12}$ que expressa o processo interpretativo entre elas ocorrido pela tradução do discurso cristão para as línguas indígenas.

A tradução não era apenas a habilidade de falar a língua de outro, mas a capacidade de reformular os pensamentos e as ações de acordo com as formas aceitas pelo colonizado. ${ }^{13}$ Exemplos dessa definição de tradução podem ser encontrados nos trabalhos de Estenssoro e Agnolin. Eles analisam o campo semântico da terminologia cristã usada nos textos missionários como expressão de uma política sincrética por parte do religioso, ao optar por fazer o amalgamento entre culturas diferentes pelo ato de tradução. As diferentes operações lingüísticas usadas no discurso cristão na língua indígena (empréstimos, neologismos e perífrases) eram formas de hibridismo do ato comunicativo da evangelização. ${ }^{14}$ Nessa última corrente, o uso das línguas indígenas nas fontes missionárias representa o espaço discursivo preferencial para captar a linguagem fruto da mediação entre índios e colonizadores. ${ }^{15}$

Tal perspectiva teórica permitiria definir o uso do tupi nos confessionários como diferenciado da cultura tradicional tupi. Diálogos de perguntas e respostas entre o penitente e o missionário não teriam semelhanças com situações comunicativas da cultura tradicional indígena. Assim, no caso do trabalho aqui apresentado, o confessionário de 1751 representaria uma forma de uso da língua tupi em novo contexto social e com novos sentidos.

\footnotetext{
${ }^{11}$ Adone Agnolin, Catequese e Tradução: gramática cultural, religiosa e lingiiistica do encontro catequético e ritual nos séculos XVI - XVII, in: Paula Montero (org.), Deus na aldeia: missionários, indios e mediação cultural, São Paulo, Editora Globo, 2006.

${ }^{12}$ Paula Montero (org.), Deus na aldeia: missionários, indios e mediação cultural, São Paulo, Editora Globo, 2006, p. 10.

${ }^{13}$ Vicente Rafael, op.cit., p. 210.

${ }^{14}$ Adone Agnolin, Catequese e Tradução: gramática cultural, religiosa e lingüística do encontro catequético e ritual nos séculos XVI - XVII, in: Paula Montero (org.), Deus na aldeia: missionários, indios e mediação cultural, São Paulo, Editora Globo, 2006, p. 173.

${ }^{15}$ John Manuel Monteiro, Tupis, Tapuias e Historiadores: Estudos de História Indígena e do Indigenismo, Tese apresentada para o Concurso de Livre Docência, Departamento de Antropologia, Campinas: IFCH - Unicamp, 2001, p. 36-52.
} 


\section{Contextualização do manuscrito tupi de 1751}

O confessionário de 1751 é parte de um códice pertencente à Biblioteca Nacional do Rio de Janeiro. O manuscrito contém um conjunto de textos auxiliares da evangelização em tupi: dicionário, gramática, orações, preceitos religiosos, diálogos de pergunta e resposta sobre a doutrina, lista de parentesco, catálogo religioso anual e nome dos dias da semana. O trecho religioso do códice da Biblioteca Naciona ${ }^{16}$ é bastante reduzido, se comparado ao universo contido nos catecismos tupi impressos. ${ }^{17}$ Mas não é uma redução apenas do tamanho do texto religioso, como também do tempo de exposição do índio à rotina cristã.

Um indício da redução do tempo de evangelização pode ser acompanhado pela comparação entre os catálogos anuais presentes no catecismo manuscrito de 1751 e naquele impresso em 1686. A versão de 1751 aponta para pouco mais de uma dezena de dias religiosos, ${ }^{18}$ em oposição aos mais de 60 listados no catecismo de Araújo (1686). ${ }^{19}$ Os motivos para a redução da rotina cristã, sinalizada no texto de 1751 , teriam sido a diminuição do tempo de exposição à doutrina cristã no cotidiano do índio da missão e o domínio menor da língua geral por parte de muitos dos catecúmenos.

A redução do tempo da evangelização foi resultado da intensificação da exploração do trabalho indígena a partir do Regimento das Missões de 1686. ${ }^{20}$ Essa legislação aumentou de dois para seis meses o tempo de trabalho obrigatório dos índios. Um índio remeiro das tropas de resgate, por exemplo, estava fora da missão entre novembro (ou dezembro) e junho. No seu regresso, tinha que fazer a roça entre os meses de julho e setembro. ${ }^{21}$ No cômputo

${ }^{16}$ Anônimo, Vocabulario de lingoa brasilica, Rio de Janeiro, Fundação Biblioteca Nacional, 1751, fólios 76-90.

${ }^{17}$ Antônio de Araújo, Catecismo Brasilico Da Doutrina Christãa, Com O Cerimonial Dos Sacramentos, छ Mais Actos Parochiae, 2. ed., Lisboa, Na Officina Miguel Deslandes, 1686; João Felipe Bettendorff, Compêndio Da Doutrina Christãa Na Lingua Portuguesa E Brasílica, Lisboa, Imprensa Miguel Deslandes, 1687.

${ }^{18}$ Anônimo, Vocabulario de Lingoa Brasílica, Rio de Janeiro, Fundação Biblioteca Nacional, 1751, p. 89.

${ }^{19}$ Antônio de Araújo, Catecismo Brasilico da Doutrina Christãa, Com O Cerimonial dos Sacramentos, $\mathscr{E}$ Mais Actos Parochiaes, 2. ed., Lisboa, Na Officina Miguel Deslandes, 1686, p. 120.

${ }^{20}$ José Oscar Beozzo, Leis e Regimentos das Missões, Política Indigenista no Brasil, São Paulo, Edições Loyola, 1983.

${ }^{21}$ Representação que fez a Companhia de Jesus do Estado do Maranhão a El Rei, pelas reparações, e desordens que padecem no mesmo Estado, Manuscrito da Biblioteca do Rio de Janeiro, s.d. 
final, um índio adulto, do sexo masculino, permanecia na missão sob a rotina da doutrina cristã cerca de três meses por ano apenas.

A diminuição do conhecimento do tupi por parte de muitos catecúmenos das missões do Pará está ligada à mudança na composição etnolingüística da região. Os tupinambá, grupo inicial de muitas das missões jesuíticas no século XVII, tinham se tornado uma minoria um século depois, devido às mortes pelas epidemias. Eles foram substituídos por índios de outras famílias lingüísticas não-tupi. ${ }^{22} \mathrm{Na}$ conjuntura de 1751, o Rio Negro, onde não havia grupos de origem tupi, foi a principal região de onde se trouxeram os índios para recompor a população das missões do Pará.

\section{Tradução de texto tupi setecentista com base na análise lingüística}

A tradução interlinear será o ponto de partida para verter o texto tupi para o português. Esse procedimento consiste em identificar e segmentar um enunciado em formas lexicais mínimas recorrentes, com duplo valor semântico: um, o literal, remetendo ao uso corrente na língua; o outro, com valor semântico transfigurado (em geral para fugir a remissões às palavras-tabus) específico para o discurso religioso. A segmentação de formas no texto foi baseada nas informações dos dicionários coloniais e das análises sobre o tupi colonial (Barbosa, ${ }^{23}$ Monserrat, ${ }^{24}$ Rodrigues ${ }^{25}$ ). Abaixo, uma ilustração de tradução interlinear (os números em colchetes, acompanhados por M [mulher] ou H [homem], remetem para a transcrição e tradução em anexo).

\begin{tabular}{|l|l|}
\hline Transcrição & Nde anáma retê? [M.4] \\
\hline Tradução interlinear & $\begin{array}{l}\text { Nde [Possessivo; } 2^{\mathrm{a}} \text { pessoa singular] anáma } \\
\text { [parente] } r \text {-[contigüidade] } \text { etê [verdadeiro] }\end{array}$ \\
\hline Proposta de tradução em português & (Ele é) seu parente de verdade? \\
\hline
\end{tabular}

\footnotetext{
${ }^{22}$ João Daniel, Tesouro descoberto no Máximo Rio Amazonas, Dois volumes, Rio de Janeiro, Fundação Biblioteca Nacional, 1976, p. 20.

${ }^{23}$ Pe. Antonio Lemos Barbosa, Curso de Tupi Antigo. Gramática, Exercício, Textos, Rio de Janeiro, Livraria São José, 1956.

${ }^{24}$ Ruth Maria Monserrat, "O tupi do século XVIII (tupi-médio)”, in: José Ribamar Bessa Freire \& Maria Carlota Rosa, Linguas Gerais. Política Lingüistica na América do Sul no período colonial, Rio de Janeiro, Eduerj, 2000, p. 185-194.

${ }^{25}$ Aryon Dall'Igna Rodrigues, Linguas brasileiras. Para o conhecimento das línguas indígenas, São Paulo, Edições Loyola, 1986.
} 
Uma das utilidades da tradução interlinear para a pesquisa historiográfica é permitir destrinchar os processos de composição lexical usados pelos missionários na construção do discurso cristão em tupi. Por exemplo, a tradução interlinear de beijo "chupar a boca" sugere a hipótese de que na cultura tupi não haveria esse ato como parte do jogo amoroso. O confessionário utiliza pitêr, associado a "chupar" e "chuchar" no dicionário de 1751, e acrescenta juru (boca) ("Você chupa a boca?" [M.17]). Para os índios, beijar deve ter parecido um ato mais próximo das curas dos pajés.

Não foi possível traduzir integralmente todas as perguntas, como a de número M.34. Em alguns casos, foi proposta uma explicação tentativa, como, por exemplo, com os verbos -icô e -ricô. O verbo -rikô tem grande recorrência no diálogo da confissão. Ele foi empregado em 15 das 36 perguntas às mulheres e 10 daquelas dirigidas aos homens. Dicionários e gramáticas coloniais atribuíam a -icô (raiz intransitiva) os sentidos de "estar", "viver", "morar". Há exemplos de emprego de -icô para uma ação tão casta para o missionário como viver de dízimos ("Viver de esmolas. Icó Tupana potaba pupê"). Já ricô ou recô (verbo transitivo, com a estrutura interna $r$-icô, aparentemente opaca para os usuários no período colonial) tem o sentido regular, neutro, de "ter". Como explicar o seu emprego recorrente no sexto mandamento como se referindo a "não fornicarás"?

Uma pista para a extensão do sentido de -ricô para o ato sexual veio do verbete de um dos dicionários que relacionava -icô (intransitivo) com copular (“Copula ter. Amenõ. Vel aicó recê"). ${ }^{27}$ Compreende-se mais facilmente, então, dada a relação de -icô com -recô, a passagem de "viver com" (-icô intransitivo) para "fornicar, possuir alguém" (-recô transitivo). Isso se daria ao nível pragmático, no contexto da confissão. No diálogo entre confessor e penitente surgiam sentidos específicos para formas tupi regulares, tais como o de ter cópula com, para -icô/-ricô. Com o tempo, -ricô passa a ter uso praticamente absoluto.

Uma interpretação para o missionário usar verbo -icô/-rîco e não outros mais populares para designar o ato sexual (por exemplo, suruc em M.23, H.27 e H.28) foi a postura de recato que o confessor deveria ter com o penitente ao falar sobre o sexo. O missionário autor do confessionário de 1751 aconselha cautela nesse tópico ("confessor deve ser muito acautelado e prudente que

${ }^{26}$ Anônimo, Diccionario da Lingua geral do Brasil que se falla em todas as villas, lugares e aldeas deste vastissimo Estado, Escrito na Cidade do Pará, Coimbra, Biblioteca da Universidade de Coimbra, 1771.

${ }^{27}$ Anônimo, Vocabulario da Lingua Braะil, Lisboa, Biblioteca Nacional, s.d., p. 55. 
em Lugar de dar medecina, para fechar as chagas, naõ da causticos, para abrir novas feridas, ensinando muitas vezes, o que o penitente naõ sabe com demaziadas preguntas, e nisto resalvo aminha conciencia"). ${ }^{28}$

Esse recato ao falar do sexo levava o missionário a usar o termo tupi mbaé (coisa) para se referir à vagina (M.31) ou ao pênis (M.18). Não que ele não use palavras "deshonestas". Para a pergunta M.23, H.27 e H.28 ele usa suruc, que um dos dicionários tupi setecentista traduz como "fornicote", mencionando ser uma palavra "deshonesta" e muito empregada pelos "tapuias" ${ }^{29}$ Se suruc é popular na fala dos índios, com o sentido de fornicar, esse verbo está pouco representando na situação de diálogo do missionário com o penitente.

Suruc, no dicionário de 1751, tem o valor semântico de romper. ${ }^{30}$ Sua extensão de uso para copular está presente nos mitos dos índios Urubu, da família lingüística tupi, documentado por Francis Huxley. ${ }^{31}$

\section{Perguntas sobre o sexto mandamento do confessionário}

O papel das perguntas nos confessionários europeus era ajudar o padre a ter informações que o penitente, por esquecimento ou por vergonha, não teria dado durante o exame de consciência. No contexto colonial, as perguntas eram o próprio guia do diálogo entre padre e penitente durante a confissão. Esse diálogo, realizado por uma sucessão de perguntas e respostas, sugere que os missionários não teriam conseguido internalizar o exame de consciência dos pecados como parte daquele cerimonial. ${ }^{32}$

O sexto mandamento da lei de Deus (não fornicarás), no manuscrito de 1751, inclui também o nono (não cobiçarás a mulher do próximo). Quase todas as perguntas pedem sim ou não como resposta. Algumas delas estavam

\footnotetext{
${ }^{28}$ Anônimo, Vocabulario de lingoa brasilica, Rio de Janeiro, Fundação Biblioteca Nacional, 1751, p. 84

${ }^{29}$ Anônimo, Diccionario da Lingua geral do Brasil que se falla em todas as villas, lugares e aldeas deste vastissimo Estado. Escrito na Cidade do Pará, Coimbra, Biblioteca da Universidade de Coimbra, 1771.

${ }^{30}$ Anônimo, Vocabulario de lingoa brasilica, Rio de Janeiro, Fundação Biblioteca Nacional, 1751, p. 82 .

${ }^{31}$ Francis Huxley, Selvagens amáveis. Um antropologista entre os índios Urubus do Brasil, v. 316, Coleção Brasiliana, São Paulo, Companhia Editora Nacional, 1963.

${ }^{32}$ Serge Gruzinski, "Aculturación e individualización: Modalidades e impacto de la confesión entre los indios nahuas de México. Siglos XVI - XVIII", Cuadernos para la historia de la evangelización en América Latina, v. 1, Cuzco, Centro Bartolomé de Las Casas, 1986, p. 9-108.
} 
encadeadas e direcionadas para diferentes penitentes. De 1 a 10, as perguntas têm como destinatário uma mulher casada. De 11 até o final (à exceção de M.33) elas se dirigem a uma índia, tanto casada como solteira. Nesse caso, em vez de mena (marido), surge o termo rapixara, com o sentido da categoria cristã do "próximo" (M. 25, 29, 35, 36/H.30).

Esse termo, diz Lemos Barbosa, ${ }^{33}$ faria parte do léxico religioso criado pelos missionários, baseado no termo -apixara, que tem sentido de "semelhante". O termo é neutro em relação ao gênero e tivemos dificuldade em determinar a que sexo se refere o termo na locução nde rapixara (teu semelhante? tua semelhante?). Para traduzir esse termo usamos companheiro(a).

Entre a primeira e a décima pergunta, o missionário quer saber se uma mulher casada mantinha relações poligâmicas, ao copular com outro homem (apyába), além do marido. Caso a índia respondesse que sim, o missionário avaliava a gravidade do pecado procurando saber alguns dados sobre esse homem: se era casado ou não (M.2), se era parente da penitente (M.4) ou do seu marido (M.3). Essas perguntas investigavam se não havia agravantes, como manter relações sexuais com pessoas com laços de consangüinidade e cunhadio. ${ }^{34}$

Como passo seguinte, o confessor queria conhecer a freqüência do ato por meio de duas perguntas. Uma delas segue o estilo do confessionário europeu, ao pedir o número de vezes que ela praticou o ato (M.5). Na pergunta seguinte (M.6), ele retoma o mesmo pedido de informação pela freqüência do ato, mas dessa vez quer saber se a índia faz o ato todos os dias ou só de vez em quando (M.6). A adaptação do pedido de número preciso em M.5 (quantas vezes) para M.6, que solicita uma informação imprecisa (cada dia ou de vez em quando), indicaria que não houve a internalização da técnica de quantificar o pecado da parte dos índios. ${ }^{35}$

Entre as perguntas 14 e 19, o missionário quer saber quais ações a índia praticava com o parceiro: dançar (M.14), abraçar (M.16), beijar (M.17), se masturbar (M.31, 35, 36) etc. Uma das perguntas remetia ao costume tupi da esposa ser a responsável por conseguir uma nova mulher para o marido (M.33). A versão masculina dessa pergunta é H.29:

\footnotetext{
${ }_{33}^{33}$ Pe. Antonio Lemos Barbosa, Curso de Tupi Antigo. Gramática, Exercício, Textos, Rio de Janeiro, Livraria São José, 1956, p. 383.

${ }^{34}$ Martin de Azpilcueta, Manual de confesores y penitentes, Coimbra, Joan de Barreyro, 1560, p. 387.

${ }^{35}$ Serge Gruzinski, op.cit., 1986, p. 20.
} 
P. Nde câ̂ ramê erecenoi ucár cunhám amô nde remiricô rupĥ, ou amô abâ rupî? [H.29] (Você quando bêbado mandou sua esposa ou alguém chamar uma mulher?)

O missionário não estava obrigado a seguir fielmente as perguntas contidas no confessionário de 1751 ("naõ te atenhas aosobre dito confissionario, que ele só serve para hua preciza necessidade"). ${ }^{36}$ Mas esse confessor, apesar de aconselhar aos colegas a extrapolarem aquele formulário, ele mesmo se restringiu a um repertório padronizado de perguntas, presente em outro manuscrito, como o de 1750. A vantagem para o missionário de ter um repertório de perguntas preestabelecidas era ganhar tempo, particularmente no período da quaresma, em que todos na aldeia deveriam se confessar.

\section{Algumas diferenças nas perguntas dirigidas a homens e mulheres}

Entre as 36 perguntas direcionadas às mulheres, sete delas são iguais, sem nenhuma alteração, às dirigidas aos homens (M.2, 3, 4, 5, 6, 11, 12, 13). Outras cinco fazem ajustes em relação aos termos referentes ao gênero, como a substituição do termo de esposa (temericô/remericô) para marido (mena), de mulher (cunhã) para homem (apyába). A última coluna do anexo faz a remissão entre as perguntas semelhantes para ambos sexos.

Um exemplo da diferença na forma empregada pelo missionário para as mulheres e para os homens era o uso da reduplicação (com sentido freqüentativo) do verbo nas perguntas às mulheres, ausente na versão equivalente dirigida aos homens. O sentido freqüentativo do verbo, composto pela repetição de uma ou mais sílabas do radical do verbo, indicava a continuidade ou freqüência da ação (M.14, 15, 19, 24, 29, 31, 35, 36). Seu emprego para a mulher pressupõe que ela continuava praticando a ação, enquanto, para os homens, $o$ missionário queria saber se eles já haviam feito, mas não investigava se estava havendo continuidade.

Um exemplo da diferença de postura do missionário ao se dirigir a mulheres e a homens está na pergunta M.32, dirigida às mulheres, e na sua versão para os homens (H.32). No caso da mulher, o padre explicita várias categorias masculinas (rapazinho, adulto, branco ou padre) que ela poderia ter olhado com desejos sexuais (M.32). Na versão para o homem, apenas se

\footnotetext{
${ }^{36}$ Anônimo, Vocabulario de lingoa brasílica, Rio de Janeiro, Fundação Biblioteca Nacional, 1751, p. 84 .
} 
interroga se quando o índio vê uma "mulher mais bonita" ele teria desejos sexuais (H.32).

\section{Conclusã̃o}

O confessor do documento de 1751 se mostrava recatado ao perguntar sobre sexo para homens e mulheres. Ele compartilhava a postura do século XVIII de silenciar sobre esse tema. ${ }^{37}$ Tal postura não está presente no confessionário tupi do século XVI, associado ao nome de Anchieta. Nesse texto, palavras como tapopé (vulva) e taconha (pênis) foram usadas sem serem substituídas por eufemismos como mbaé (coisa), como no de 1751. No confessionário de Anchieta, a pergunta sobre se a mulher se masturba consiste numa longa descrição, muito diferente da versão velada de 1751 (ver M.31):

Erepokókpe nde rapopé resé ipekábo, eñemopiránga, ipypirá, ipypekábo, ejejukábo? (Tocaste em tuas virilhas [vulva] abrindo-as, avermelhando-te, alargando-as, separando-as, ferindo-te?) (Anchieta, 1992). ${ }^{38}$

A postura de evitar falar abertamente sobre sexo ou sobre partes do corpo no confessionário de 1751 teria levado à formação de um léxico específico para a confissão. Ser um índio cristão incluiria aprender o sentido específico que o missionário dava a alguns termos tupi na situação da confissão. O índio deveria aprender não apenas que -rico significava copular e mbaé certas partes do corpo, mas, sobretudo, que havia interdição de se falar de sexo explicitamente, mesmo nas situações de diálogo em que este era o principal tópico, como na parte da confissão referente ao sexto mandamento da Lei de Deus.

\footnotetext{
${ }^{37}$ Michel Foucault, História da Sexualidade I: A vontade de saber, 16. ed., Rio de Janeiro, Edições Graal, 1988.

${ }^{38}$ José de Anchieta, Doutrina cristã. Tomo 2: Doutrina autógrafa e confessionário, Obras Completas, v. 10, Introdução histórico-literária, tradução e notas do Pe. Armando Cardoso SJ, São Paulo, Edições Loyola, 1992, p. 95.
} 


\section{Anexo}

Transcrição e tradução das perguntas referentes ao sexto mandamento de Deus no confessionário de 1751 (fl.82-83), pertencente à Biblioteca Nacional do Rio de Janeiro. A coluna à direita remete às perguntas semelhantes direcionadas aos homens e as mulheres. Os colchetes remetem ao sentido literal e os parênteses às elipses. A tradução foi realizada por Ruth Monserrat.

\begin{tabular}{|c|c|c|c|}
\hline & Pergunta em tupi & Tradução & \\
\hline H.1 & $\begin{array}{l}\text { P. Erericô cunhám amô nde } \\
\text { remiricô çuî? }\end{array}$ & $\begin{array}{l}\text { Você copulou [ter, estar] com } \\
\text { outra mulher além da tua } \\
\text { esposa? }\end{array}$ & M.1 \\
\hline H.2 & P. Mendaçára ou mendaçareýma? & (Ela era) casada ou solteira? & M.2 \\
\hline H.3 & P. Nde anáma retê? & $\begin{array}{l}\text { (Ela era) sua parenta de } \\
\text { verdade? }\end{array}$ & M.4 \\
\hline H.4 & P.Nde remiricô anáma? & $\begin{array}{l}\text { (Ela era) parenta de tua } \\
\text { mulher? }\end{array}$ & M.3 \\
\hline H.5 & P. Mobýr eiî ta erericô? & $\begin{array}{l}\text { Quantas vezes você copulou } \\
\text { [ter, estar] (com ela)? }\end{array}$ & M.5 \\
\hline H.6 & $\begin{array}{l}\text { P. Erericô ára jabê jabê ou amô } \\
\text { ramê nhóte? }\end{array}$ & $\begin{array}{l}\text { Você copulou [ter, estar] (com } \\
\text { ela) todos os dias ou só de vez } \\
\text { em quando? }\end{array}$ & M.6 \\
\hline H.7 & $\begin{array}{l}\text { P. Eremopyaýba, ou erericô aýb } \\
\text { nde remiricô imoâ cunhám recê?? }\end{array}$ & $\begin{array}{l}\text { Você entristeceu [tornar o } \\
\text { fígado ruim] ou tratou mal } \\
\text { sua esposa por causa de outra } \\
\text { mulher? }\end{array}$ & M.7 \\
\hline H.8 & $\begin{array}{l}\text { P. Opoîr ucár oáne indébo Paŷ } \\
\text { imoâ cunhám çuî? }\end{array}$ & $\begin{array}{l}\text { O padre já mandou você se } \\
\text { abster de outra(s) mulher(es)? }\end{array}$ & M.8 \\
\hline H.9 & $\mathrm{P}$ Eremiéng miéng mbaê ixupê? & Você ficou dando coisas a ela? & M.9 \\
\hline H.10 & $\begin{array}{l}\text { P. Erejemocoár purýb cecê nde } \\
\text { remiricô çuî? }\end{array}$ & $\begin{array}{l}\text { Você negociou vantagem com } \\
\text { sua mulher por causa disso? }\end{array}$ & M.10 \\
\hline H.11 & P. Aicobê erericô amô? & $\begin{array}{l}\text { Porventura você copulou [ter, } \\
\text { estar] com outra? }\end{array}$ & M.11 \\
\hline H.12 & P. Erericô mendaçareýma amô? & $\begin{array}{l}\text { Você copulou [ter, estar] com } \\
\text { uma não-casada? }\end{array}$ & M.12 \\
\hline H.13 & P. Eremombúca cunhatém amô? & $\begin{array}{l}\text { Você deflorou [furar] alguma } \\
\text { moça? }\end{array}$ & \\
\hline H.14 & $\begin{array}{l}\text { P. Oacýpe eremombúca ou } \\
\text { cemimotára rupî?? }\end{array}$ & $\begin{array}{l}\text { Você a deflorou [furar] por tua } \\
\text { vontade ou pela vontade dela? }\end{array}$ & \\
\hline H.15 & P. Erericô céraýma amô? & $\begin{array}{l}\text { Você copulou [ter, estar] (com) } \\
\text { alguma não-batizada [sem } \\
\text { nome]? }\end{array}$ & M.13 \\
\hline
\end{tabular}




\begin{tabular}{|c|c|c|c|}
\hline & Pergunta em tupi & \begin{tabular}{|c|} 
Tradução \\
\end{tabular} & \\
\hline H.16 & $\begin{array}{l}\text { P. Erericô cerâ cunhám amô, nde } \\
\text { oataçába rupî? }\end{array}$ & $\begin{array}{l}\text { Você copulou [ter, estar] com } \\
\text { alguma mulher cristã durante } \\
\text { suas viagens? }\end{array}$ & \\
\hline H.17 & $\begin{array}{l}\text { P. Ereporacéi cunhám etâ } \\
\text { irúnamo? }\end{array}$ & Você dançou com mulheres? & M.14 \\
\hline H.18 & $\begin{array}{l}\text { P. Eremojarû cunhám etâ } \\
\text { amôramô, ou cunhã muçu etâ? }\end{array}$ & $\begin{array}{l}\text { Você brincou/gracejou alguma } \\
\text { vez com mulheres ou moças? }\end{array}$ & M.15 \\
\hline H.19 & $\begin{array}{l}\text { P. Erejumáne amô ramê cunhám } \\
\text { amô? }\end{array}$ & $\begin{array}{l}\text { Você abraçou [enrolar] alguma } \\
\text { vez com mulher? }\end{array}$ & M.16 \\
\hline H.20 & P. Erejurû pitér cunhám amô? & $\begin{array}{l}\text { Você beijou [chupar a boca] } \\
\text { alguma mulher? }\end{array}$ & M.17 \\
\hline H.21 & $\begin{array}{l}\text { P. Erepocóc iembaê recê amô } \\
\text { ramê? }\end{array}$ & $\begin{array}{l}\text { Você apalpou a coisa dela } \\
\text { alguma vez? }\end{array}$ & M.18 \\
\hline H.22 & P. Nde raipór ucár ixupê ipô rupî? & $\begin{array}{l}\text { Você mandou ela te masturbar } \\
\text { [provocar ejaculação] com a } \\
\text { mão dela? }\end{array}$ & \\
\hline H.23 & $\begin{array}{l}\text { P Nde raiporé nde pô pupê } \\
\text { amô ramê nde remimotára rupî̀, } \\
\text { erejemimotára ramê cunhã recê? }\end{array}$ & $\begin{array}{l}\text { Você alguma vez se masturbou } \\
\text { [provocar ejaculação] com sua } \\
\text { mão por sua vontade quando } \\
\text { desejava uma mulher? }\end{array}$ & \\
\hline H.24 & $\begin{array}{l}\text { P. Nde raipóre nde poçauçúpe } \\
\text { amô ramê? }\end{array}$ & $\begin{array}{l}\text { Você ejaculou durante seu } \\
\text { sonho alguma vez? }\end{array}$ & \\
\hline H.25 & P. Nde rorýb coitê cecê? & $\begin{array}{l}\text { Você ficou contente com isso } \\
\text { no fim? }\end{array}$ & M.21 \\
\hline H.26 & $\begin{array}{l}\text { P.Erericô pecô mimbábo cunhám } \\
\text { amô? }\end{array}$ & $\begin{array}{l}\text { Você copulou [ter, estar] pecô } \\
\text { (?) com algum animal fêmea de } \\
\text { criação? }\end{array}$ & \\
\hline H.27 & P. Eresurúca aba amô? & $\begin{array}{l}\text { Você copulou [romper, } \\
\text { penetrar] com alguém? }\end{array}$ & \\
\hline H.28 & P. Nde suruca abâ amô? & $\begin{array}{l}\text { Você foi copulado [rompido/ } \\
\text { penetrado] por alguém? }\end{array}$ & M.23 \\
\hline H.29 & $\begin{array}{l}\text { P. Nde caû ramê erecenoi ucár } \\
\text { cunhám amô nde remiricô rupî, } \\
\text { ou amô abâ rupî? }\end{array}$ & $\begin{array}{l}\text { Você quando bêbado mandou } \\
\text { sua mulher ou algum homem } \\
\text { chamar alguma mulher? }\end{array}$ & $\begin{array}{c}\text { M.29 } \\
\text { ou } \\
\text { M.24 }\end{array}$ \\
\hline H.30 & $\begin{array}{l}\text { P.Eremoçarai ramê nde rapixára } \\
\text { etá erúnamo, erenheéng ixupê, } \\
\text { aricô racô kyuum? çupî rupî, ou } \\
\text { gereguáya rupî? }\end{array}$ & $\begin{array}{l}\text { Quando você brinca com seus } \\
\text { companheiros, você diz a eles } \\
\text { eu copulei [ter, estar com] } \\
\text { [kyuum ?]? De verdade ou de } \\
\text { mentira? }\end{array}$ & M.25 \\
\hline
\end{tabular}




\begin{tabular}{|l|l|l|l|}
\hline & \multicolumn{1}{|c|}{ Pergunta em tupi } & \multicolumn{1}{c|}{ Tradução } & M.30 \\
\hline H.31 & $\begin{array}{l}\text { P. Erejemimotár etê amô ramê } \\
\text { cunhám recê, nde puáne nhóte, } \\
\text { nitio recê, erericô cunham nde } \\
\text { robake, eremonhang aráma nde } \\
\text { rimimotára? }\end{array}$ & $\begin{array}{l}\text { Você desejou muito alguma } \\
\text { mulher só por vontade, por } \\
\text { nada, você teve uma mulher } \\
\text { junto a ti, para satisfazer a sua } \\
\text { vontade? }\end{array}$ & M.32 \\
\hline H.32 & $\begin{array}{l}\text { P. Erecipiá ramê cunham iporánga } \\
\text { porýb, ere nheéng nde puápe, } \\
\text { tomáramo xericô quaê? }\end{array}$ & $\begin{array}{l}\text { Ao olhar uma mulher mais } \\
\text { bonita você falou para si } \\
\text { mesmo [para seu fígado] } \\
\text { tomara que eu a copulasse [ter, } \\
\text { estar com]? }\end{array}$ & M. \\
\hline
\end{tabular}

Perguntas dirigidas às mulheres:

\begin{tabular}{|c|c|c|c|}
\hline & Pergunta em tupi & \begin{tabular}{|c|} 
Tradução \\
\end{tabular} & \\
\hline M.1 & $\begin{array}{l}\text { P[ergunta]. Erericô apyába amô } \\
\text { nde mena çuî? }\end{array}$ & $\begin{array}{l}\text { Você copulou [ter, estar] com } \\
\text { outro homem além de seu } \\
\text { marido? }\end{array}$ & H.1 \\
\hline M.2 & $\begin{array}{l}\text { P. Mendaçára, ou } \\
\text { mendaçareýma? }\end{array}$ & $\begin{array}{l}\text { (Ele era) casado ou não- } \\
\text { solteiro? }\end{array}$ & H.2 \\
\hline M.3 & P. Nde mena anáma? & $\begin{array}{l}\text { (Ele era) parente de teu } \\
\text { marido? }\end{array}$ & H.4 \\
\hline M.4 & P. Nde anáma retê? & $\begin{array}{l}\text { (Ele era) seu parente de } \\
\text { verdade? }\end{array}$ & H.3 \\
\hline M.5 & P. Mobýr eiî tâ erericô? & $\begin{array}{l}\text { Quantas vezes você copulou } \\
\text { [ter, estar] (com ele)? }\end{array}$ & H.5 \\
\hline M.6 & $\begin{array}{l}\text { P. Erericô ára jabé jabé, ou amô } \\
\text { ramê nhóte? }\end{array}$ & $\begin{array}{l}\text { Você copulou [ter, estar] (com } \\
\text { ele) todos os dias ou só de vez } \\
\text { em quando? }\end{array}$ & H.6 \\
\hline M.7 & $\begin{array}{l}\text { P. Eremopyaýba, ou erericô aýba } \\
\text { nde mena imoâ apyaba recê? }\end{array}$ & $\begin{array}{l}\text { Você entristeceu [tornar o } \\
\text { fígado ruim] ou tratou mal seu } \\
\text { marido por causa de outro } \\
\text { homem? }\end{array}$ & H.7 \\
\hline M.8 & $\begin{array}{l}\text { P. Opuîr ucár oáne indébo Pay } \\
\text { imoâa apyába çuî? }\end{array}$ & $\begin{array}{l}\text { O padre já mandou você } \\
\text { abster-se de outro(s) } \\
\text { homem(ns)? }\end{array}$ & H.8 \\
\hline M.9 & $\begin{array}{l}\text { P. Eremeeng ixupé mbaê mirim } \\
\text { mirim erericô â? }\end{array}$ & $\begin{array}{l}\text { Você deu a ele coisa pequenina } \\
\text { que você tinha? }\end{array}$ & H.9 \\
\hline M.10 & $\begin{array}{l}\text { P. Erejemocoár porýb cecê nde } \\
\text { mena çuî? }\end{array}$ & $\begin{array}{l}\text { Você negociou vantagem com } \\
\text { seu marido por causa disso? }\end{array}$ & H.10 \\
\hline M.11 & P. Aicobê erericô amô? & $\begin{array}{l}\text { Porventura você copulou [ter, } \\
\text { estar] com outro? }\end{array}$ & H.11 \\
\hline
\end{tabular}




\begin{tabular}{|c|c|c|c|}
\hline & Pergunta em tupi & Tradução & \\
\hline M.12 & P. Erericô mendaçareýma amô? & $\begin{array}{l}\text { Você copulou [ter, estar] com } \\
\text { um não-casado? }\end{array}$ & H.12 \\
\hline M.13 & P. Erericô céraýma amô? & $\begin{array}{l}\text { Você copulou [ter, estar] com } \\
\text { algum não-batizado [sem- } \\
\text { nome]? }\end{array}$ & H.15 \\
\hline M.14 & $\begin{array}{l}\text { P. Ereporacê racéya apyába etâ } \\
\text { erúnamo? }\end{array}$ & $\begin{array}{l}\text { Você ficou dançando com } \\
\text { homens? }\end{array}$ & H.17 \\
\hline M.15 & P. Eremojarû jarû apyába etá? & $\begin{array}{l}\text { Você ficou brincando/ } \\
\text { gracejando com homens? }\end{array}$ & H.18 \\
\hline M.16 & P. Erejumán? & Você abraçou [enrolar]? & H.19 \\
\hline M.17 & P.Erejurû pitér? & Você beijou [chupar a boca]? & H.20 \\
\hline M.18 & P.Erepocóc imbaê recê? & Você apalpou a coisa dele? & H.21 \\
\hline M.19 & P. Erepirô piróc ixupê? & $\begin{array}{l}\text { Você ficou esfregando } \\
\text { [descascar] ele (o pênis dele)? }\end{array}$ & H.22 \\
\hline M.20 & $\begin{array}{l}\text { P. Erericô apyába nongára nde } \\
\text { poçau cupê? }\end{array}$ & $\begin{array}{l}\text { Você copulou [ter, estar] com } \\
\text { um homem em sonho? }\end{array}$ & H.24 \\
\hline M.21 & P. Nde rorýb erepác reire? & $\begin{array}{l}\text { Você ficou feliz depois que } \\
\text { acordou? }\end{array}$ & H.25 \\
\hline M.22 & $\begin{array}{l}\text { P. Erericô mimbábo apyába } \\
\text { recê? }\end{array}$ & $\begin{array}{l}\text { Você copulou [ter, estar] com } \\
\text { animal de criação macho? }\end{array}$ & H.26 \\
\hline M.23 & P. Nde surúca apyába amô? & $\begin{array}{l}\text { Você foi copulada [rompida/ } \\
\text { penetrada] por algum homem? }\end{array}$ & H.28 \\
\hline M.24 & $\begin{array}{l}\text { P. Nde caû ramê erejemeen } \\
\text { meéng apyába etá çupê? }\end{array}$ & $\begin{array}{l}\text { Você quando bêbada, ficou se } \\
\text { entregando aos homens? }\end{array}$ & H.29 \\
\hline M.25 & $\begin{array}{l}\text { P. Eremoçárai ramê nde rapixára } \\
\text { etá irúnamo, erenheéng ixupê, } \\
\text { arico racô xerî, ajubéte moçaráya } \\
\text { rupî nhóte? }\end{array}$ & $\begin{array}{l}\text { Ao brincar/gracejar com suas } \\
\text { companheiras você falou } \\
\text { para elas eu copulei mesmo } \\
\text { [racô xerî? a ainda que só de } \\
\text { brincadeira? }\end{array}$ & H.30 \\
\hline M.26 & P. Erericô cerâ Pay amô? & $\begin{array}{l}\text { Você por acaso copulou [ter, } \\
\text { estar] com algum Padre? }\end{array}$ & \\
\hline M.27 & $\begin{array}{l}\text { P. Eremombeû coitê nde } \\
\text { rapixára etâ çupî: nde } \\
\text { jemopirîng potár recê?? }\end{array}$ & $\begin{array}{l}\text { Você contou depois para suas } \\
\text { companheiras por querer se } \\
\text { gabar? }\end{array}$ & \\
\hline M.28 & P. Erericó carýba amô? & $\begin{array}{l}\text { Você copulou [ter, estar] com } \\
\text { algum branco? }\end{array}$ & \\
\hline M.29 & $\begin{array}{l}\text { P. Nde caû ramê erejenón jenón } \\
\text { nde rapixára irúnamo erericô } \\
\text { aráma apyába nongára? }\end{array}$ & $\begin{array}{l}\text { Quando bêbada você ficou } \\
\text { se deitando com uma } \\
\text { companheira para copular } \\
\text { como homem? }\end{array}$ & \\
\hline M.30 & $\begin{array}{l}\text { P. Erejemimotár etê amô ramê } \\
\text { apyába recê. }\end{array}$ & $\begin{array}{l}\text { Você à vezes deseja de verdade } \\
\text { um homem? }\end{array}$ & H.31 \\
\hline
\end{tabular}




\begin{tabular}{|c|c|c|c|}
\hline & Pergunta em tupi & Tradução & \\
\hline M.31 & $\begin{array}{l}\text { P. Erepoém poém, amô ramê } \\
\text { nde mbaê recê erejemimotár } \\
\text { ramê? }\end{array}$ & $\begin{array}{l}\text { Você fica pondo a mão na sua } \\
\text { coisa às vezes, quando está } \\
\text { com desejo? }\end{array}$ & H.23 \\
\hline M.32 & $\begin{array}{l}\text { P. Erecipiác ramê coromîm oçû } \\
\text { amô, ou apyába amô, ou carýba } \\
\text { ou Pa- amô erenheén nde } \\
\text { pyápe nhóte tomarámo xaricô } \\
\text { quâê? }\end{array}$ & $\begin{array}{l}\text { Quando você olhou um } \\
\text { rapazinho ou um homem ou } \\
\text { um branco ou um Padre você } \\
\text { falou para si mesmo [apenas } \\
\text { em seu fígado] tomara que eu } \\
\text { copule [ter, estar] com ele? }\end{array}$ & H.32 \\
\hline M.33 & $\begin{array}{l}\text { P. Erecenói cunham amô nde } \\
\text { mena cope? }\end{array}$ & $\begin{array}{l}\text { Você chamou outra mulher } \\
\text { para seu marido? }\end{array}$ & H.29 \\
\hline M.34 & $\begin{array}{l}\text { P. Eremonguetâ cunham amô, } \\
\text { ou cunhatém amô, amô abá } \\
\text { çupê oaráma, nde jecuai ramé } \\
\text { cecê oaráma? }\end{array}$ & $\begin{array}{l}\text { Você contou para mulher, } \\
\text { ou moça, ou alguém, para se } \\
\text { favorecer através disso? [?] }\end{array}$ & \\
\hline M.35 & $\begin{array}{l}\text { P. Erepoém poém ucár nde } \\
\text { embaê, nde rapixára etâ cupêe? }\end{array}$ & $\begin{array}{l}\text { Você mandou as suas } \\
\text { companheiras tocarem na tua } \\
\text { coisa? }\end{array}$ & \\
\hline M.36 & $\begin{array}{l}\text { P. Erepoém póem amô nde } \\
\text { rapixára mbaê eremoçárai ramê? }\end{array}$ & $\begin{array}{l}\text { Você ficou tocando na coisa de } \\
\text { sua companheira quando você } \\
\text { estava brincando? }\end{array}$ & $\begin{array}{l}\text { H.22 } \\
\text { H.21 }\end{array}$ \\
\hline
\end{tabular}

